\title{
CADÊ A EMPRESA QUE ESTAVA AQUI? PROCESSO DE FALÊNCIA E REESTRUTURAÇÃO DA KODAK À LUZ DA TEORIA DO CICLO DE VIDA DA FIRMA
}

\author{
Inajá Allane Santos Garcia ${ }^{1}$, Dante Baiardo Cavalcante Viana Junior ${ }^{\Omega}$, Wenner Glaucio Lopes Lucena \\ Universidade Federal do Pará - UFPA, Belém, PA (Brasil) \\ $\Omega$ Instituto Universitário de Lisboa - ISCTE-IUL, Lisboa (Portugal)
}

\section{DETALHES DO ARTIGO}

\section{Histórico do Artigo:}

Recebido: 08 de Fevereiro de 2019

Aceito: 09 de Março de 2020

Disponível online: 01 de maio de 2020

Sistema de revisão "Double blind review"

Editor Científico

Ilan Avrichir

\section{Palavras-chaves:}

Caso de Ensino

Teoria dos ciclos de vida da firma Kodak

\begin{abstract}
RESUMO
Objetivo: À luz da Teoria dos Ciclos de Vida da Firma, o presente caso de ensino se propõe a apresentar a trajetória percorrida pela Kodak - gigante do mercado fotográfico durante praticamente todo o século XX -, buscando relacionar as características empresariais oriundas das mudanças ocorridas ao longo do tempo com cada um dos estágios do ciclo de vida de uma organização.

Método: Os dados para construção do contexto histórico da empresa Kodak foram retirados de diversas fontes da mídia tradicional, priorizando-se o próprio sítio eletrônico da empresa, jornais digitais de alto impacto internacional assim como revistas eletrônicas nacionais.

elevância/originalidade: Este caso de ensino oferece um debate acerca da Teoria dos Ciclos de Vida da Firma, por meio da análise da trajetória de uma empresa real, em um contexto internacional, permitindo a identificação de características empresariais que podem suscitar o ciclo de vida atual de uma organização.

Contribuições teóricas/metodológicas: Busca-se ainda uma triangulação entre a Teoria dos Ciclos de Vida da Firma, as características da empresa Kodak e as diversas mudanças ocorridas diante das diversas decisões tomadas no sentido de restruturação da empresa
\end{abstract}

\section{CASO KODAK}

\subsection{Introdução}

O objeto de estudo desse caso é a empresa Eastman Kodak Company, conhecida mundialmente como Kodak, de origem norte-americana. Frente aos fatos históricos que serão apresentados a seguir, torna-se evidente que diversos ciclos de vida foram vivenciados pela Kodak, os quais vão desde o seu nascimento ao final da década de 1870 até os dias atuais, em que a empresa tenta se manter no mercado por meio de novas abordagens estratégicas, diferentes daquelas iniciais desenvolvidas no início da organização.

A história da Kodak no mercado é marcada por diferentes etapas, dentre elas o momento em que a empresa vivenciou o ápice de sua expansão no mercado mundial de fotografia em 1975, marcado pela criação da primeira câmera digital, alguns momentos de turbulência ocasionados pelas sucessivas trocas de CEOs com pensamentos e estratégias distintas, e também o momento do pedido de concordata no ano 2012. Após esses ciclos a empresa ainda continua a existir no mercado, porém atuando principalmente em outras atividades e no mercado fotográfico de forma secundária.

De uma pequena empresa do sul dos Estados Unidos à maior empresa mundial e atualmente buscando sobrevivência, é possível se observar na Kodak diferentes características do ponto de vista econômico-financeiro, como também diversas performances gerenciais adaptadas às várias situações ao longo de seu ciclo de vida. Destarte, à luz da Teoria dos Ciclos de Vida da Firma, o presente caso de ensino se propôs a apresentar a trajetória percorrida pela Kodak, buscando relacionar as características empresariais oriundas das mudanças ocorridas ao longo do tempo com cada um dos estágios do ciclo de vida de uma organização. Dessa forma, busca-se uma triangulação entre a Teoria dos Ciclos de Vida da Firma, as características da empresa Kodak e as diversas mudanças ocorridas diante das diversas decisões tomadas no sentido de restruturação da empresa. 


\subsection{Contexto Histórico: Entendendo o Caso KODAK}

A Eastman Kodak Company - hoje conhecida mundialmente como Kodak -, fabricante do mercado norte americano de filmes, suprimentos fotográficos e fornecedora de serviços e produtos de imagem digital, tem sede atual em Rochester, Nova York. A história da empresa tem início em 1879, quando George Eastman introduziu no mercado uma máquina de revestimento por emulsão que proporcionou a produção em massa de chapas secas fotográficas. Esse foi um momento importante na época, uma vez que, até então, os fotógrafos tinham que revestir uma espécie de placa com produtos químicos frescos e molhados cada vez que quisessem tirar uma foto (Kodak, 2018).

Dois anos após, George Eastman formou uma parceria com Henry A. Strong e juntos deram início a Eastman Dry Plate Company, a qual posteriormente, em 1884, se transformou em Eastman Dry Plate and Film Company. Finalmente em 1888 surge o nome Kodak, e o mesmo foi reconhecido no mercado a partir do lançamento de uma câmera com esse nome, a qual possuía o slogan "Você aperta o botão - nós fazemos o resto", nascendo, portanto, a fotografia instantânea (Kodak, 2018). Após esse reconhecimento perante o mercado e algumas alterações societárias na empresa, em 1892 a companhia se tornou a Eastman Kodak Company como é denominada até os dias de hoje.

Nos anos subsequentes, a Kodak ganhou ainda mais mercado por meio de uma rápida expansão internacional, estabelecendo em 1897 uma subsidiária na França e em 1899 um centro de distribuição no Canadá. Após essas expansões a empresa continuou se destacando no mercado por produzir e aperfeiçoar produtos fotográficos como, por exemplo, filmes fotográficos, máquinas reveladoras de filme, câmeras aéreas utilizadas durante a primeira Guerra Mundial, dentre outros (Kodak, 2018). O crescimento não se limitava ao mercado, mas também ao número de empregos que a empresa gerava, chegando a 20 mil no ano de 1927. A evolução da empresa nesse período era notável.

A Kodak investiu pesado em filmes para as máquinas fotográficas e quando a fotografia colorida foi introduzida era uma das poucas empresas que possuía conhecimento necessário e entendimento dos processos para obter sucesso, chegando a alcançar US\$ 1 bilhão nas suas vendas no ano de 1962 (Lucas \& Goh, 2009).

Após tantas evoluções no mercado fotográfico e cinematográfico, em 1975, o engenheiro chefe da Kodak foi o pioneiro ao inventar a primeira câmera digital, do mundo, a qual possuía um protótipo do tamanho de uma torradeira e que captava imagens em preto e branco com resolução de 0,01 megapixels (Kodak, 2018), sendo essa a primeira versão da câmera digital lançada ao mercado, ainda em sua forma elementar. A partir de então, a Kodak recebe posição de destaque no mercado fotográfico: sendo parte desse resultado em função do lançamento da primeira câmera digital. Como reflexo disso, em 1976 a Kodak destacou-se no mercado de filmes e câmeras dos Estados Unidos, chegando a dominar mais de $80 \%$ desse mercado (Lucas \& Goh, 2009). Em 1980, juntamente com a comemoração do seu centésimo aniversário, a Kodak anuncia a sua entrada no mercado de diagnóstico clínico, o que proporcionou vendas no ano seguinte de 10 bilhões de dólares.

No mesmo ano, 1993, houve a substituição de Kay Whitmore, presidente da empresa por George Fisher. Este era visto pelo conselho como um "homem digital", responsável por fazer um investimento em conjunto com o governo chinês em uma joint venture, pois ele acreditava que a China era um mercado emergente com grande potencial para a fotografia (Lucas \& Goh, 2009). O fato é que após sucessivas trocas de CEOs com pensamentos e estratégias distintas, bem como a cultura conservadora da empresa e a aliança realizada por Fisher com o governo chinês, a Kodak não conseguiu acompanhar de maneira tempestiva todas as atualizações que o mercado demandava, abrindo assim, espaço para as empresas concorrentes como, por exemplo, a Fuji. Como uma empresa conservadora, a Kodak possuía uma cultura e estrutura rígida e burocrática e isso de certa forma não contribuiu para uma resposta rápida que deveria ter sido dada às novas tecnológicas que estavam revolucionando o processo de captura e compartilhamento de imagens à época (Lucas \& Goh, 2009). 


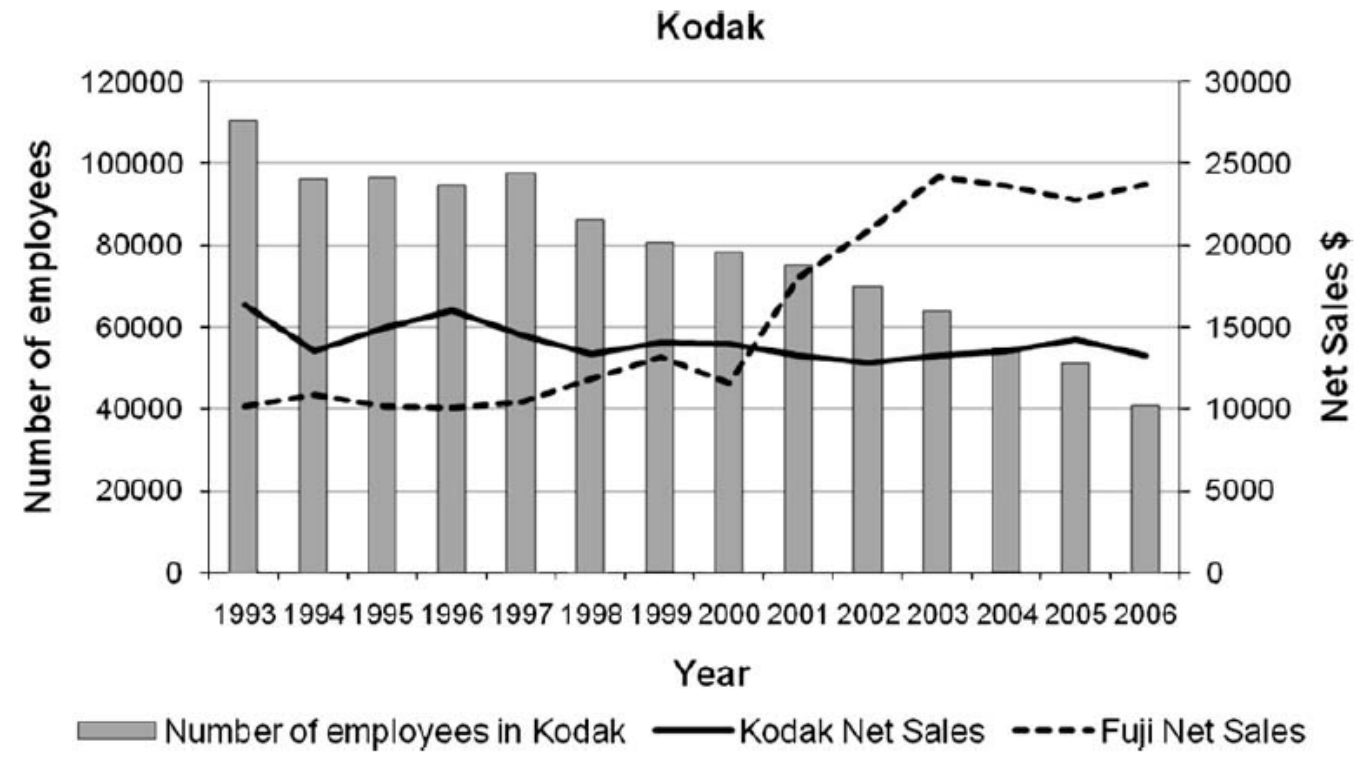

Figura 1 - Kodak: Vendas líquidas e número de empregados no período de 1993 a 2006.

Fonte: Lucas e Goh (2009)

No ano seguinte, em 1994, percebe-se que a Kodak começou a reduzir sua mão-de-obra, quase que de forma gradativa, por meio de demissões e aposentadorias, indicando que a empresa estava passando por dificuldades, conforme Figura 1. É possível verificar também que nesse ano as vendas da Kodak ainda estavam superiores as vendas da Fuji, porém, a partir de 1998 as mesmas foram ficando equivalentes até que, após o ano 2000 a Fuji passou a faturar mais do que a Kodak.

No mercado, em 1997 as vendas de câmeras digitais estavam aumentando $75 \%$ ao ano, enquanto as vendas de câmeras de filmes aumentavam apenas $3 \%$. Nessa época, havia muitos novos participantes na fotografia digital, principalmente empresas de eletrônicos japonesas (Lucas \& Goh, 2009).

Mais tarde, por volta de 1999 a Kodak começou a realizar transações de venda de suas operações relacionadas às impressoras digitais, copiadoras e conjuntos de rolos para a Heidelberger Druckmaschinen AG - multinacional alemã fabricante de equipamentos de precisão para a indústria de mídia impressa -, anunciando novos sistemas relacionados à realização de mamografias e sistemas de radiografia digital para captura de imagens de raios-X. Paralelo a esses novos serviços, a companhia continuou produzindo câmeras digitais e produtos relacionados à fotografia.

Já no início da década de 2000, mais precisamente em 01 de abril de 2004, a imprensa anuncia a saída da Kodak do índice Dow Jones Industrial Average, juntamente com outras duas empresas: AT\&T Corporation e International Paper Company. A empresa, que era listada no índice desde 1930, veio a ser removida oficialmente em 08 de abril daquele mesmo ano. Apesar do editor chefe do índice, na ocasião John Prestbo, ter comunicado no mesmo ano não haver claros motivos para a remoção da empresa, a imprensa em geral noticiou o fato de maneira bastante negativa para o mercado (Day Business Journal, 2004).

Apesar da repercussão negativa acerca da saída da empresa do índice Down Jones em 2004, no ano seguinte a empresa ainda ocupava a posição de empresa № 1 líder em câmeras digitais nos Estados Unidos (Reuters, 2018). Alguns anos depois, já em 2009, a empresa lançou um programa de reciclagem de câmeras descartáveis, atingindo o montante de 1,5 bilhões de máquinas recicladas. Nesse mesmo ano, a empresa decide suspender a distribuição de dividendos em dinheiro (Reuters, 2018), o que poderia ter sido entendido como algum sinal a respeito da situação financeira da empresa. Poucos anos depois, em 2011, lançou sua primeira câmera digital à prova d'água e novas ofertas foram lançadas para atender a demanda por álbuns de fotos alta qualidade e outros produtos fotográficos. Paralelo a isso, a Kodak revela ter contratado profissionais especialistas em reestruturações organizacionais (Reuters, 2018), dando indícios de que alguma coisa no cenário organizacional passaria por mudanças. 
Finalmente em 2012, a Kodak anunciou uma nova estrutura de negócios (Reuters, 2018), e com a reorganização, realizou uma série de mudanças para focar a empresa nos mercados comerciais, mudanças essas que incluíram a desativação de negócios relacionados a capturas digitais e a venda de ativos da Kodak Gallery (serviços de fotografia online).

Após uma extensa negociação, a Kodak deixou de funcionar e entrou oficialmente com pedido de concordata em janeiro de 2012, por meio do Capítulo 11 da Lei de Falências do Código Estados Unidos, listando ativos de U\$ 5,1 bilhões e passivos de U\$ 6,75 bilhões, segundo fontes do Jornal Financier Worldwide (2018). As informações referentes à atual situação da empresa à época foram divulgadas em seu Relatório Anual de 2012. Durante o processo de falência, a Kodak, com 121 anos, leiloou seu portfólio de patentes de imagem digital por U\$ 527 milhões e vendeu sua unidade personalizada de imagens e documentos por cerca de U\$ 650 milhões. A venda dos principais negócios da empresa foi pressagiada pela incapacidade da Kodak de obter valor significativo para seu extenso portfólio de patentes. A empresa esperava levantar cerca de U\$ 2 bilhões para suas 1.100 patentes, mas, em parte devido a uma disputa com a Apple, o portfólio foi vendido para um consórcio liderado pela Intellectual Ventures e RPX Corporation por apenas U\$ 525 milhões (Financier Worldwide, 2018), dificultando ainda mais situação da ex-gigante do mercado fotográfico mundial.

Para fundamentar o processo de concordata, a empresa mencionou nos autos do processo uma série de fatores para o pedido de falência, entre eles a recessão global de 2008, o fracasso da Kodak em acompanhar o surgimento da fotografia digital, que removeu a demanda por filmes fotográficos tradicionais e o peso dos altos custos dos fundos de pensão. Sobre o processo falência, o então Chairman da companhia, Philip Cullimore, em entrevista ao The World Association of Newspapers and News Publishers [WAN-IFRA] (2012) comentou:

"Sejamos claros: a Kodak entrou com pedido de concordata no Capítulo 11, nos EUA. O Capítulo 11 do Código de Falências dos EUA permite que as empresas se reestruturem enquanto continuam a operar. As empresas que arquivam sob o Capítulo 11 têm o objetivo de sair do Capítulo 11, mais forte e mais eficiente. Mais importante ainda, a Kodak não está saindo do mercado. A Kodak não está liquidando. As subsidiárias da Kodak não americanas não estão incluídas nos registros e continuarão a operar normalmente.

Os clientes da Kodak continuarão recebendo os mesmos altos padrões de qualidade de produtos e serviços que eles esperam. A Kodak continuará a fazer o que sempre fez, e é trazer produtos e serviços para o mercado que ajudam nossos clientes a fazer mais, melhor e mais rápido. (...)

O portfólio de produtos, soluções e software da Kodak para impressoras de jornais continuará a oferecer eficiência e produtividade líderes de mercado para nossos clientes. Além disso, anunciaremos novos produtos significativos que trarão benefícios adicionais aos nossos clientes".

Já no ano seguinte, o então CEO da empresa, Antônio M. Perez, também em entrevista ao USA Today (2013) mencionou:

"Eu não recomendaria [o processo de falência] para ninguém, mas se você tem custos legados, não vejo nenhuma outra maneira de lidar com eles. Era a coisa certa a fazer pela Kodak. Foi a escolha certa.

[Isso] tem sido doloroso para muitas pessoas, tanto para mim quanto para qualquer outra pessoa. Foi a decisão certa, tão dolorosa quanto é. Pessoas, inclusive eu, perderam a pensão. As pessoas perderam a compensação diferida, inclusive eu. Assumo total responsabilidade por todas as decisões que tomamos para criar uma nova empresa. Não vou assumir responsabilidades pelos legados à empresa por outra pessoa.

Nós mantivemos uma empresa viva. A empresa está muito bem alinhada. Tem um grande futuro na frente dela".

Em 2013, a empresa voltou a negociar ações na New York Exchange Stock (NYSE), sob o novo símbolo KODK e, no ano seguinte, comemorou o recadastramento na NYSE, tocando o sino de reabertura do capital da empresa, sob o comando do CEO Jeff Clarke (Kodak, 2018).

Algumas das mudanças vividas pela Kodak ao longo dos anos estão refletidas por meio dos demonstrativos contábeis, como evidenciado na Figura 2. No ano seguinte ao início do período crítico da Kodak, o qual ocorreu a partir de 2009, é possível observar sucessivos resultados negativos, indicando baixos índices de lucratividade quando em comparação com anos anteriores. 
Cadê a Empresa que Estava Aqui? Processo de Falência e Reestruturação da Kodak à Luz da Teoria do Ciclo de Vida da Firma

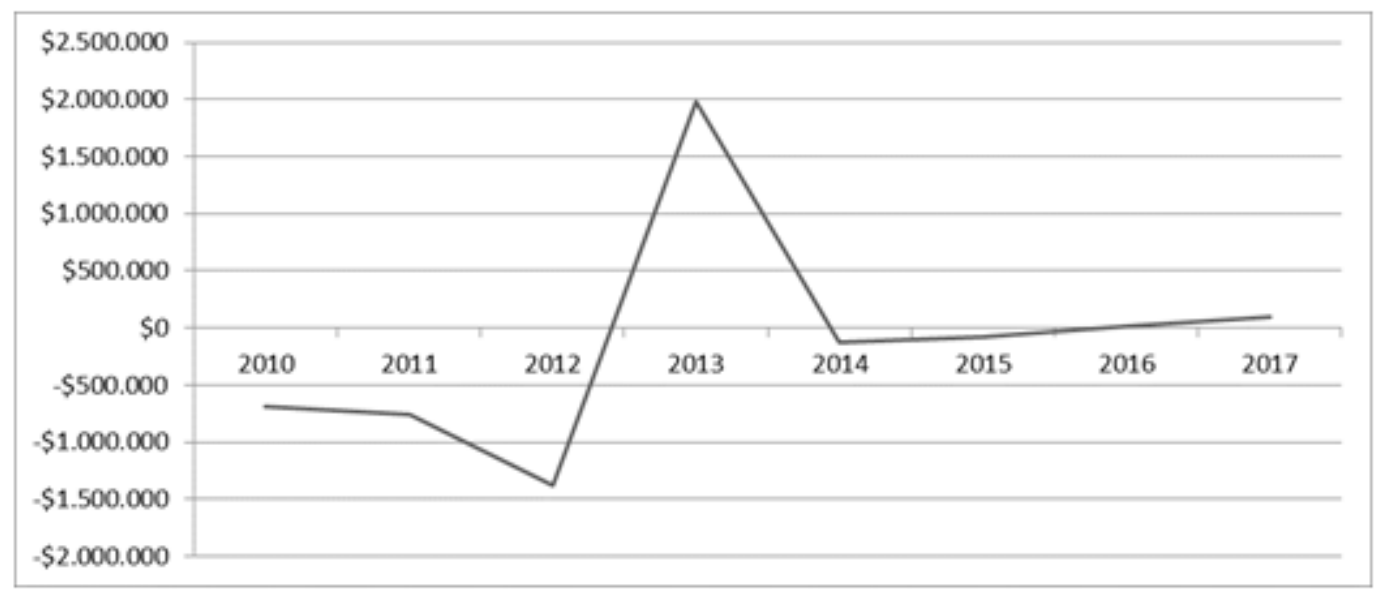

Figura 2 - Kodak: Lucro Líquido no período de 2010 a 2017.

Fonte: Thomson Reuters Eikon (2019).

Conforme a Figura 2 apresenta, em 2010 o resultado líquido da Kodak foi negativo em US\$ 687 milhões, sendo o seu pior resultado no ano de 2012, quando a empresa entrou com o pedido de concordata junto à corte norte-americana. Em 2013, com a volta da empresa à bolsa da NYSE, os seus resultados subiram subitamente chegando a US\$ 1.985 milhões. Desde esse ano então, a empresa luta para manter seus resultados positivos, porém só obtém respostas positivas a partir do ano de 2016. Percebe-se, portanto que os dados financeiros refletem o histórico de queda e recuperação da empresa nesse período entre a turbulência e a reestruturação da companhia no mercado.

Mais recentemente, em 2018 a Kodak, em parceria com a Wenn Digital, anunciou que irá criar sua própria criptomoeda, informação essa que fez as ações da Kodak aumentarem seus preços em mais de $105 \%$ no mercado norte-americano, mais especificamente na NYSE (Exame, 2018). A empresa ainda opera no mercado norte-americano e comercializa impressoras jato de tinta coloridas e, com menor destaque, também continua comercializando produtos no Brasil.

A atual diretora de marca da empresa, Danielle Atkins, em uma recente entrevista ao MarketingWeek (2018) comentou sobre a nova fase da empresa e sua postura frente a um mercado mais dinâmico e competitivo. Para Daniella, o atual objetivo da empresa é fazer com que as pessoas conheçam e amem a marca Kodak, como fizeram no passado.

Nesse sentido, enquanto a empresa está atualmente $80 \%$ focada em tecnologias de impressão comercial, Danielle Atkins explica que uma parte essencial de seu papel nos últimos três anos foi trazer a marca do consumidor de volta em um "grande caminho". "A Kodak quase esqueceu que era uma marca de consumo enorme", explica ela. "Nós vendemos tecnologias para a indústria de impressão, e essa é a maior parte dos negócios, mas temos focado muita energia na reconstrução dos negócios dos consumidores, criando nossos próprios produtos e licenciando a marca com uma estratégia muito clara para que esses produtos estar dentro da economia da imagem" (MarketingWeek, 2018).

Percebe-se então que, desde sua retomada mais forte ao mercado, seria possível destacar o uso de novas tecnologias, negócios digitais internos ou acordos de licenciados. A estratégia futura fará com que a Kodak procure por categorias mais relevantes para a marca nas quais possa desenvolver novos negócios de inicialização. Exemplo disso é a recente criação de um dos negócios digitais emergentes, o Kodaklt: uma plataforma usada por marcas como Uber e Deliveroo para contratar fotógrafos para sessões de fotos. De forma geral, os fotógrafos se registram na plataforma e, uma vez selecionadas, as empresas enviam as especificações da sessão de fotos que desejam encomendar. Após a conclusão da sessão, o fotógrafo edita as imagens e as carrega na plataforma Kodaklt, de onde o cliente baixa as fotos. A Kodak gerencia e processa todos os pagamentos e licenças em nome do fotógrafo, que tem a taxa paga diretamente em sua conta. A plataforma também possui um sistema de inteligência artificial que verifica todas as imagens antes que elas passem para o cliente para garantir que estejam dentro do padrão (MarketingWeek, 2018). 
Frente ao contexto histórico apresentado, percebe-se, portanto, a passagem da empresa por diversos ciclos de vida, entre eles uma crescente e constante expansão - atingindo patamares de liderança mundial no mercado fotográfico -, um período crítico de recessão simbolicamente representado pelo pedido de concordata em 2008, até uma reestruturação de suas atividades por meio das mais recentes ferramentas e serviços disponibilizados, com viés altamente tecnológico. Torna-se evidente, ainda, que o período de declínio da empresa deve-se não somente à falta de modernização frente ao desenvolvimento tecnológico com o advento das máquinas digitais, mas também à cultura da Kodak que contribuiu para isso e às decisões estratégicas de financiamento tomadas pelos gestores, como a má gestão de capital de terceiros, o que calhou nos altos custos dos fundos de pensão, como detalhado pelo Financier Worldwide (2018). Nesse sentido, vale salientar que a cultura de uma empresa é a responsável por definir o que é feito e o que não pode ser feito (Lucas \& Goh, 2009), e no caso da Kodak a cultura aliada as pode ter sido um fator determinante para que a empresa não acompanhasse a inovação tecnológica do processo de captura e compartilhamento de imagem. Destarte, uma cuidadosa análise do caso Kodak permite levantar uma série de decisões estratégicas relevantes que estão diretamente vinculadas ao seu nível de desenvolvimento e maturidade, como detalhado nas questões a seguir.

\subsection{Fechamento do Caso e Questões para Discussões}

A Kodak sempre buscou parcerias de sucesso, o que permitiu a sua expansão no mercado internacional. No entanto, devido a uma série de más decisões estratégicas, as quais foram somadas a um cenário econômico mundial em crise, a empresa passou por um período crítico, inclusive chegando a decretar falência junto à corte norte-americana e em seguida retomou suas atividades tentando se reerguer.

A Kodak investiu pesado em fotografia digital ao criar a primeira câmera digital, porém os gerentes de nível médio e a cultura da organização impossibilitaram a empresa de capitalizar esse investimento, ou seja, a Kodak incorreu em mudanças organizacionais e culturais devido às novas tecnologias que ameaçaram os seus modelos de negócios tradicionais (Lucas \& Goh, 2009).
Com o intuito de fomentar essa discussão acerca dos ciclos de vida vivenciados pela Kodak, são sugeridas as seguintes questões:

1. Considerando os aspectos históricos relatados na seção 1, a empresa Kodak apresentava alguns indícios de crescimento da organização, porém após a criação da primeira câmera digital, quais são os momentos das atividades operacionais da empresa que podem indicar um possível encaminhamento da empresa ao processo de falência no ano de 2012?

2. Considerando os estágios do modelo de ciclo de vida proposto por Miller e Friesen (1983, 1984), conforme Figura 3, e fazendo uma análise da história da Kodak, é possível perceber alguma semelhança no que se refere à ordem cronológica dos estágios do ciclo de vida apresentada pelos autores? Se sim, identifique quais momentos vivenciados pela empresa a direciona para cada um dos estágios elencados pelos autores. Caso negativo, discutam com os colegas qual seria a ordem dos estágios do ciclo de vida da empresa Kodak.

3. Após a decretação de falência em 2012, a Kodak se reestruturou e continua operando como sociedade de capital aberto na NYSE. Na sua percepção, a posição da empresa no mercado continuou a mesma? Justifique sua resposta.

4. Diante do exposto acerca da Teoria do ciclo de vida, no que se refere aos seus estágios, é possível perceber algumas semelhanças entre os estágios de crescimento e renascimento. Quais são as características que você consegue identificar a partir do modelo de Miller e Friesen (1983, 1984)? Aplicando isso ao Caso Kodak, é possível perceber tais semelhanças? Justifique sua resposta.

5. Em sua opinião, o fato de a empresa Kodak ter diversificado seus produtos com a possível intenção de abranger um maior público foi benéfico ou maléfico para a sua permanência no mercado? Argumente sua resposta.

\section{NOTAS DE ENSINO}

\subsection{Exposição Teórica: Teoria do Ciclo de Vida da Firma}

A forma como as organizações evoluem ao longo do tempo é algo que, de alguma maneira, vem tomando a atenção da comunidade. Pesquisadores têm procurado entender a organização na sua trajetória de vida, num primeiro momento, 
epistemologicamente desvinculada de uma abordagem vinculada à área econômica, mas com elementos que permitam compreender o seu estágio de vida e suas possibilidades de mudanças (Frezatti, Souza Bido, Mucci, \& Beck, 2017).

Teóricos do campo de estratégia e administração adotaram o modelo de ciclo de vida empresarial a partir de modelos fundamentados nas ciências biológicas e o incorporaram à pesquisa de negócios desde a década de 1960 (Hasan, Hossain, \& Habib, 2015). Chandler (1962) argumenta que a estrutura organizacional segue a estratégia de crescimento da empresa para aproveitar as oportunidades externas e dessa forma manter-se viva no mercado frente as contingências impostas às organizações.

Nesse espectro, o ciclo de vida da firma parece ter implicações importantes na gestão e estratégia de negócios. Cada estágio do ciclo de vida da empresa impõe características e demandas exclusivas que envolvem estruturas organizacionais, pessoal, estilos de liderança e processos de tomada de decisão apropriados para atender aos requisitos (Kazanjian, 1988).

O estudo do ciclo de vida das firmas investiga as possíveis alterações que a empresa sofre com o passar do tempo, pois as mudanças organizacionais ocorrem em patterns previsíveis, caracterizados por estágios de desenvolvimento em função de implicações do ambiente externo - estratégia, capacitação da gestão e recursos financeiros - e interno - competição, fatores macroeconômicos, risco político, entre outros (Costa, Macedo, Yokoyama, \& Almeida, 2017; Dickinson, 2011).

A importância do entendimento dos ciclos de vida da firma parte do pressuposto de que este modelo poderia fornecer um roteiro, identificando transições organizacionais críticas, bem como armadilhas que a organização deveria evitar ao aumentar em tamanho e complexidade. Sendo assim, um modelo preciso de ciclo de vida poderia ainda fornecer um cronograma para adicionar níveis de gerenciamento, formalizar procedimentos e sustentos organizacionais e revisar as prioridades da organização. Isso poderia ajudar os gestores a saber quando "abandonar" estratégias ou práticas passadas que apenas impedirão o crescimento futuro (Hanks, 1990).

Ao analisar a literatura abrangente acerca do ciclo de vida das organizações, percebe-se que diversos modelos foram desenvolvidos com a intenção de detectar o estágio do ciclo de vida no qual a firma poderia ser enquadrada. Dentre os diversos modelos encontrados, alguns que merecem destaque são: Miller e Friesen (1983, 1984), Lester et al (2003) e Dickinson (2011). Cada um deles parte de uma análise diferente da empresa, a qual pode ser financeira ou não, com vistas a indicar o estágio de ciclo de vida vivenciado pela organização. Miller e Friesen (1983, 1984) ao apresentarem um vasto horizonte temporal, de maneira pioneira, propôs uma sequência evolutiva entre os estágios do ciclo de vida. De forma sucinta, o modelo proposto pelos autores poderia ser representado, conforme Figura 3: 


\begin{tabular}{|c|c|c|c|}
\hline \multicolumn{4}{|c|}{ FASE DE NASCIMENTO } \\
\hline Descrição & \multicolumn{3}{|c|}{$\begin{array}{l}\text { A organização é caracterizada por uma estrutura simples e centralizada. Há poucos controles formais e sistemas } \\
\text { de informação. A organização é dominada pelo fundador, o qual concentra as decisões, prescindindo de um staff } \\
\text { especializado. Um estilo intuitivo de decisão predomina em lugar de um modelo analítico. Projetos não são } \\
\text { detalhados nem alternativas são consideradas. Poucas opiniões são levadas em conta para a tomada de decisão } \\
\text { importante. }\end{array}$} \\
\hline Atributos & $\begin{array}{l}\text { Situação/Ambiente } \\
\text { - Firma pequena } \\
\text { - Jovem } \\
\text { - Dominada pelo fundador } \\
\text { - Ambiente homogêneo, plácido }\end{array}$ & $\begin{array}{l}\text { Organização } \\
\text { - Estrutura informal } \\
\text { - Indiferenciada } \\
\text { - Poder altamente centralizado } \\
\text { - Métodos primitivos de } \\
\text { processamento de informação }\end{array}$ & $\begin{array}{l}\text { Inovação e Estratégia } \\
\text { - Inovação considerável nas linhas } \\
\text { de produto } \\
\text { - Estratégia de nicho } \\
\text { - Assume riscos substanciais }\end{array}$ \\
\hline \multicolumn{4}{|c|}{ FASE DE CRESCIMENTO } \\
\hline Descrição & \multicolumn{3}{|c|}{$\begin{array}{l}\text { A linha de produtos da organização é ampliada, e mercados são abordados de forma segmentada. A estrutura se } \\
\text { torna mais especializada, e a influência do dono na rotina administrativa diminui. Maior esforço é despendido na } \\
\text { coleta e no processamento de informação a respeito do ambiente competitivo (monitoramento), para controle do } \\
\text { desempenho financeiro dos diversos produtos e para facilitar a comunicação e coordenação entre os vários } \\
\text { departamentos. O grau de ousadia das decisões ainda está presente, mas reduzido, uma vez que mais gerentes são } \\
\text { envolvidos nas decisões, diminuindo o apetite a riscos e proatividade. }\end{array}$} \\
\hline Atributos & $\begin{array}{l}\text { Situação/Ambiente } \\
\text { - Firma com tamanho médio } \\
\text { - Mais velha } \\
\text { - Múltiplos acionistas } \\
\text { - Ambiente mais heterogêneo e } \\
\text { competitivo }\end{array}$ & $\begin{array}{l}\text { Organização } \\
\text { - Alguma formalização da estrutura } \\
\text { - Base organizacional funcional } \\
\text { - Diferenciação moderada } \\
\text { - Algo menos centralizada }\end{array}$ & $\begin{array}{l}\text { Inovação e Estratégia } \\
\text { - Ampliação do escopo de produtos } \\
\text { e mercados em áreas relacionadas } \\
\text { - Inovações incrementais nas linhas } \\
\text { de produto }\end{array}$ \\
\hline \multicolumn{4}{|c|}{ FASE DE MATURIDADE } \\
\hline Descrição & \multicolumn{3}{|c|}{$\begin{array}{l}\text { A organização é caracterizada por uma diminuição do grau de inovação. Além disso, arranjos políticos são } \\
\text { perseguidos para manter a estabilidade do ambiente, e a meta passa a ser a melhoria da eficiência e a lucratividade } \\
\text { das operações. A estrutura é mais profissionalizada, e o fundador provavelmente já se retirou. Há maior ênfase na } \\
\text { formalidade dos controles, orçamentos e indicadores de desempenho. O estilo de decisão é mais conservador, } \\
\text { menos inclinado a assumir riscos e inovações. O nível de análise é similar ao da fase anterior. }\end{array}$} \\
\hline Atributos & $\begin{array}{l}\text { Situação/Ambiente } \\
\text { - Firma maior } \\
\text { - Continua velha } \\
\text { - Propriedade dispersa } \\
\text { - Ambiente ainda mais } \\
\text { heterogêneo e competitivo }\end{array}$ & $\begin{array}{l}\text { Organização } \\
\text { - Estrutura formal e burocrática } \\
\text { - Base organizacional funcional } \\
\text { - Diferenciação moderada } \\
\text { - Centralização moderada }\end{array}$ & $\begin{array}{l}\text { Inovação e Estratégia } \\
\text { - Consolidação da estratégia de } \\
\text { produtos e mercados } \\
\text { - Foco no suprimento de mercados } \\
\text { bem definidos de forma eficiente }\end{array}$ \\
\hline \multicolumn{4}{|c|}{ FASE DE RENASCIMENTO } \\
\hline Descrição & \multicolumn{3}{|c|}{$\begin{array}{l}\text { Há mais inovações do que em qualquer outro período do ciclo de vida da organização. A diversidade de produtos } \\
\text { e mercados leva a uma estrutura divisionalizada. A direção da organização utiliza controles sofisticados para } \\
\text { monitorar o desempenho de suas divisões, a fim de orientar suas decisões estratégicas. A maior complexidade } \\
\text { exige outros tipos de controle de monitoramento ambiental e de coordenação interna, além daqueles comuns à } \\
\text { fase anterior. O estilo de decisão volta a privilegiar a inovação e o risco para gerar crescimento. }\end{array}$} \\
\hline Atributos & $\begin{array}{l}\text { Situação/Ambiente } \\
\text { - Firma muito grande } \\
\text { - Ambiente muito heterogêneo, } \\
\text { competitivo e dinâmico }\end{array}$ & $\begin{array}{l}\text { Organização } \\
\text { - Base organizacional divisional } \\
\text { - Controles, monitoramento e } \\
\text { comunicação sofisticados }\end{array}$ & $\begin{array}{l}\text { Inovação e Estratégia } \\
\text { • Estratégia de diversificação de } \\
\text { produtos e mercados, } \\
\text { movimentação para algumas áreas } \\
\text { não relacionadas }\end{array}$ \\
\hline \multicolumn{4}{|c|}{ FASE DE DECLÍNIO } \\
\hline Descrição & \multicolumn{3}{|c|}{$\begin{array}{l}\text { As organizações diminuem as reações aos estímulos do ambiente externo, tornando-se estagnadas e passando a } \\
\text { enfatizar os processos internos, mesmo sem a presença relevante de um sistema de controle. A comunicação entre } \\
\text { áreas e níveis hierárquicos é deficiente, diminuindo a capacidade de reação aos desafios. A tomada de decisão é } \\
\text { caracterizada por um alto nível de conservadorismo e centralização. A gestão das crises deixa pouco tempo para } \\
\text { a direção se dedicar à análise. }\end{array}$} \\
\hline Atributos & $\begin{array}{l}\text { Situação/Ambiente } \\
\text { - Tamanho de mercado } \\
\text { - Ambiente homogêneo e } \\
\text { Competitivo }\end{array}$ & $\begin{array}{l}\text { Organização } \\
\text { - Estrutura formal e burocrática } \\
\text { - Base organizacional funcional na } \\
\text { maioria } \\
\text { - Diferenciação e centralização } \\
\text { moderadas }\end{array}$ & $\begin{array}{l}\text { Inovação e Estratégia } \\
\text { - Baixo nível de sofisticação } \\
\text { - Corte de preços } \\
\text { - Consolidação de produtos e } \\
\text { mercados } \\
\text { - Liquidação de subsidiárias }\end{array}$ \\
\hline
\end{tabular}

Figura 3 - Modelo de ciclo de vida de Miller e Friesen (1984)

Fonte: Miller e Friesen (1983, 1984) e Necyk (2008) apud Carvalho et al. (2010). 
Cadê a Empresa que Estava Aqui? Processo de Falência e Reestruturação da Kodak à Luz da Teoria do Ciclo de Vida da Firma

Percebe-se então que o modelo de Miller e Friesen $(1983,1984)$ divide o ciclo de vida das empresas em cinco fases, sendo: nascimento, crescimento, maturidade, renascimento e declínio. Para cada um dos estágios do ciclo de vida é possível perceber uma descrição e os atributos que diferenciam os estágios quanto à situação/ambiente, organização e inovação e estratégia. Ao comparar o referido modelo com outros, é possível verificar que não seguem exatamente a mesma nomenclatura, porém, em sua maioria, eles apresentam de forma geral uma fase inicial, intermediária e final da organização.

No modelo de Lester et al (2003) por exemplo, os autores delinearam os ciclos de vida da seguinte forma: existência, sobrevivência, sucesso, renovação e declínio. A base conceitual desse modelo está amparada na contabilidade gerencial. Para tanto, os autores utilizaram a metodologia survey, permitindo que os executivos da alta gestão das empresas respondessem 53 itens relacionados à organização, a partir da qual foi possível a classificação da empresa no estágio de ciclo de vida que melhor a represente em determinado período.

Por fim, e não menos importante, destaca-se o modelo de Dickinson (2011), considerado pela literatura como o mais simples, uma vez que se utiliza apenas de informações financeiras das empresas relacionadas aos fluxos de caixa gerados e consumidos pelas organizações nas suas atividades operacionais, de investimento e de financiamento. Nesse modelo, a autora também classificou o ciclo de vida em cinco estágios, sendo: introdução, crescimento, maturidade, turbulência e declínio.

Diante dos modelos aqui citados, percebe-se a literatura que abrange o ciclo de vida das organizações e conclui-se que o mesmo pode ser abordado a partir de diversas óticas, seja a estrutura organizacional das empresas, a introdução de novos produtos no mercado e informações financeiras relacionadas às atividades desenvolvidas pelas empresas.

Diante desse contexto, pode-se argumentar então que a identificação do ciclo de vida no qual a organização está inserida, assim como suas características organizacionais são essenciais para que a gestão consiga traçar um planejamento estratégico de forma que atinja o resultado almejado. Como por exemplo, a correta identificação do status de turbulência e/ou declínio e a correta classificação do público-alvo da empresa podem ser considerados fatores chaves na reestruturação da companhia.

\subsection{Aspectos Pedagógicos}

Destarte, à luz da Teoria dos Ciclos de Vida da Firma, o presente caso de ensino propõe uma discussão acerca dos momentos vivenciados pela Kodak ao longo da sua trajetória, a qual pode ser fomentada por meio das características organizacionais evidenciadas anteriormente, bem como dos fatos e dados históricos, econômicofinanceiros e do ambiente no qual a firma se encontra, subsidiando respostas aos questionamentos propostos (Questão de 1 a 5).

Quanto ao método do caso, Avrichir (2013) comenta que para que seja possível estimular a capacidade analítica dos discentes, o caso de ensino precisa ter um nível mínimo de complexidade possibilitando uma discussão e reflexão crítica a respeito do conteúdo abordado. Nesse sentido, o presente caso de ensino tem como objetivo pedagógico proporcionar aos alunos um debate acerca da Teoria dos Ciclos de Vida da Firma, por meio da análise da trajetória de uma empresa real, a Kodak, permitindo a identificação de características empresariais que podem suscitar o ciclo de vida atual de uma organização. Assim, ressalta-se também a finalidade pedagógica deste caso, a qual consiste em permitir que os discentes desenvolvam a capacidade crítica quanto às escolhas e motivos que podem conduzir as organizações a cada um dos ciclos de vida. O caso, em geral, destina-se ao público da área de negócios - Administração, Contabilidade, Economia e Gestão Financeira - com interesses específicos no entendimento da Teoria dos Ciclos de Vida da Firma e da sua relevância, bem como suas implicações teóricas e práticas para os acadêmicos e as organizações.

Nesse sentido, acredita-se que o caso possa ser discutido tanto à nível de graduação como de pósgraduação, apesar de, no geral, perceber-se um maior nível de interesse por parte de estudantes de mestrado e doutorado no campo das Ciências Sociais Aplicadas, uma vez que estudantes desse nível possuem maior probabilidade de cursarem disciplinas que possuem o assunto da Teoria dos Ciclos de Vida da Firma inserido no conteúdo programático. 
Quanto a forma de aplicação do caso de ensino na aula, sugere-se trabalhar com a temática relacionada à Teoria do Ciclo de Vida. É importante que a referida teoria seja conhecida pelos alunos, de forma que os discentes entendam-na e consigam identificar os diversos "sinais" que poderiam ser indicativos dos estágios dos ciclos de vida das organizações. Além de artigos seminais sobre a temática, abordados durante a discussão teórica desse caso, acredita-se que a Figura 3 - apresentada na seção da Exposição Teórica -, possa ser utilizada como material de suporte para esse propósito.

Diversos são os modelos de ciclo de vida apresentados pela literatura (Anthony, \& Ramesh, 1992; Diamond, 1991; Dickinson, 2011; Gort, \& Klepper, 1982; Hanks, 1990; Klepper, 1996; Lester, Parnell, \& Carraher, 2003; Lumpkin, \& Dess, 2001; Miller, \& Friesen, 1984; Mueller, 1972). Dentre tais modelos recebe destaque o desenvolvido por Miller e Friesen (1984) que de acordo com as evidências do estudo de Gomes et al (2010), é o modelo mais utilizado em pesquisas empíricas. Além disso, Miller e Friesen são considerados por Carvalho, Saraiva e Frezatti (2010) os principais autores das publicações norte-americanas relacionadas ao ciclo de vida das firmas, uma vez que possuem o trabalho mais citado.

Acredita-se que o conhecimento de vários modelos pode proporcionar aos alunos uma maior capacidade crítica. No entanto, este caso de ensino foca em um modelo de aspecto qualitativo (Miller \& Friesen, 1983, 1984), devido não só a sua relevância no contexto científico, como também a uma maior abertura na discussão de assuntos relacionados à temática que dificilmente poderia ser obtida por meio de modelos de caráter quantitativos (Anthony, \& Ramesh, 1992; Dickinson, 2011). O modelo qualitativo apresentado pelos autores Miller e Friesen permite uma análise de vários aspectos organizacionais a fim de detectar em qual estágio a firma se encontra, sendo assim, proporciona uma análise mais aprofundada de todas as características, estratégias e processos que são desenvolvidos pela organização, mas que não são possíveis de quantificação e consequentemente de servir como inputs para os modelos quantitativos.

\subsubsection{Sugestão para o planejamento da aula}

Após esse entendimento teórico geral que deve ser trabalhado inicialmente, a sugestão é no sentido de que o caso de ensino seja enviado a todos os alunos com antecedência, para que os discentes realizem uma leitura prévia para adentrar no cenário ao qual a Kodak vivenciou e, dessa forma, fomentar o desenvolvimento de uma visão crítica e ampla a respeito do contexto histórico da empresa. Apesar do esforço dos autores em apresentar no caso os principais pontos relacionados aos estágios do ciclo de vida da empresa, a critério do professor (a), sugerir-se-ia ainda que os alunos buscassem informações adicionais sobre o caso em fontes alternativas. A busca autônoma dos alunos por informações adicionais poderia enriquecer mais a discussão e, talvez, criar um maior envolvimento deles com o caso, no sentido inclusive de entenderem a importância dos eventos em si.

Logo após, em um terceiro momento, com alunos estando cientes do contexto histórico do caso, espera-se que o professor da disciplina organize pequenos grupos, cerca de 3 ou 4 alunos, para que os discentes conversem entre si e debatam a respeito do que conseguiram compreender na junção entre os fatos históricos da empresa e a teoria apresentada. Feito isso, os grupos tentam responder às questões propostas e, assim, apresentar para os demais colegas e professor quais as respostas que foram possíveis alcançar a partir da discussão.

O último momento, portanto, seria o compartilhamento das respostas de cada um dos grupos, com a necessária participação do professor após as respostas obtidas. Nessa parte final, sugerese ainda que o professor tenha responsabilidade ao pontuar aquilo que está de acordo com a Teoria do Ciclo de Vida da Firma e quais os pontos não observados pelos alunos que poderiam também contribuir para uma melhor discussão frente às questões elencadas.

\subsubsection{Fontes dos dados}

Os dados para construção do contexto histórico da empresa Kodak foram retirados de diversas fontes da mídia tradicional, priorizando-se o próprio sítio eletrônico da empresa, jornais digitais de alto impacto internacional assim como revistas eletrônicas nacionais.

Nesse contexto, tomou-se como fundamental a preocupação com mecanismo de fact-checking na perspectiva de evitarem-se informações inverídicas ou distorcidas do caso. 
Cadê a Empresa que Estava Aqui? Processo de Falência e Reestruturação da Kodak à Luz da Teoria do Ciclo de Vida da Firma

\section{REFERÊNCIAS}

Avrichir, I. (2013). O que eu avalio, hoje, quando me pedem um parecer sobre um caso de ensino. Revista Brasileira de Casos de Ensino em Administração. Disponível em < http://bibliotecadigital.fgv.br/ojs/index.php/gvcasos Larticle/view/8846>. Recuperado em 22 jan 2020.

Carvalho, K. L., Saraiva , A. F. Jr., Frezatti, F., \& Costa, R. P. (2010). A contribuição das teorias do ciclo de vida organizacional para a pesquisa em contabilidade gerencial. Revista de Administração Mackenzie, 11(4), 98-130.

Chandler, A. D., 1962. Strategy and structure: chapters in the history of the American enterprise. Massachusetts Institute of Technology Press, Cambridge, MA.

Costa, W. B., Macedo, M. A. S., Yokoyama, K. Y., Almeida, J. E. F. (2017). Análise dos Estágios de Ciclo de Vida de Companhias Abertas no Brasil: Um Estudo com Base em Variáveis Contábil-Financeiras. Brazillian Business Review, 14(3), 304-320.

Day Business Journal (2004). Kodak removed from Dow index. Disponível em <https://www.bizjournals.com/dayton/stories/2004/ 03/29/daily29.html>. Recuperado em 19 ago 2019.

Diamond, D. W. (1991). Monitoring and reputation: The choice between bank loans and directly placed debt. Journal of Political Economy, 99(4), 689-721.

Dickinson, V. (2011) Cash Flow Patterns as a Proxy for Firm Life Cycle. The Accounting Review, 86(6), 1969-1994.

Exame (2018). Kodak cria seu próprio bitcoin e ações sobem mais de 100\%. Disponível em $<$ https://exame.abril.com.br/mercados/kodak-criaseu-proprio-bitcoin-e-acoes-sobem-mais-de-100/ $\geq$. Recuperado em 05 jun 2018.

Financier Worldwide (2013). Eastman Kodak finally exits bankruptcy. Disponível em $<$ https://www.financierworldwide.com/eastmankodak-finally-exits-bankruptcy/\#.Wuy-k4gvxPY>. Recuperado em 04 mai 2018.
Frezatti, F., de Souza Bido, D., Mucci, D. M., \& Beck, F. (2017). Estágios do ciclo de vida e perfil de empresas familiares brasileiras. Revista de Administração de Empresas, 57(6), 601-619.

Hanks, S. H. (1990). The organization life cycle: Integrating content and process. Journal of Small Business Strategy, 1(1), 1-12.

Hasan, M. M., Hossain, M., \& Habib, A. (2015). Corporate life cycle and cost of equity capital. Journal of Contemporary Accounting \& Economics, 11(1), 4660.

Kazanjian, R. K., 1988. Relation of dominant problems to stages growth in technology-based new ventures. Academy of Management Journal, 31(2), 257-279.

Klepper, S. (1996). Entry, exit, growth, and innovation over the product life cycle. The American Economic Review, 86(3), 562-583.

Kodak (2019). Executive Leadership: Danielle (Dany) Atkins. Disponível em https://www.kodak.com/gb/en/corp/executive profile/Dany Atkins/default.htm. Recuperado em 16 set 2019.

Lester, D. L., Parnell, J. A., \& Carraher, S. (2003). Organizational life cycle: a five-stage empirical scale. International Journal of Organizational Analysis, 11(4), 339-354.

Lucas, H. C., Jr. \& Goh, J. M. (2009). Disruptive technology: How Kodak missed the digital photography revolution. Journal of Strategic Information Systems, 18, 46-55.

Lumpkin, G. T., \& Dess, G. G. (2001). Linking two dimensions of entrepreneurial orientation to firm performance: The moderating role of environment and industry life cycle. Journal of Business Venturing, 16(5), 429-451.

MarketingWeek (2018). From skate to streetwear: Kodak plans to bring back its consumer brand in a 'big way'. Disponível em https://www.marketingweek.com/kodak-bring-backconsumer-brand/. Recuperado em 16 set 2019. 
Miller, D., \& Friesen, P. H. (1983). Strategy-making and environment: The third link. Strategic Management Journal, 4(3), 221-235.

Miller, D., \& Friesen, P. H. (1984). A longitudinal study of the corporate life cycle. Management Science, 30(10), 1161-1183.

Mueller, D. C. (1972). A life cycle theory of the firm. The Journal of Industrial Economics, 199-219.

Reuters (2018). Timeline: The Kodak moment fades. Disponível em https://www.reuters.com/article/uskodak-timeline/timeline-the-kodak-moment-fades-
idUSTRE80I1XN20120120. Recuperado em 05 jul 2018.

USA Today (2013). Kodak CEO: 'We kept a company alive'. Disponível em <https://eu.usatoday.com/story/money/business/20 13/09/04/kodak-bankruptcy-ceorestructuring/2761425/>. Recuperado em 21 ago 2019.

WAN-IFRA (2012). Interview with Kodak's Philip Cullimore. Disponível em <https://www.wanifra.org/articles/2012/04/03/interview-with-kodaksphilip-cullimore>. Recuperado em 20 ago 2019.

\section{Sobre os Autores:}

Inajá Allane Santos Garcia - Universidade Federal do Pará - UFPA, Belém, PA (Brasil). E-mail: inajaallane@hotmail.com Orcid id: http://orcid.org/0000-0002-7844-9743

Dante Baiardo Cavalcante Viana Junior - Instituto Universitário de Lisboa - ISCTE-IUL, Lisboa (Portugal). E-mail: dantebcviana@gmail.com Orcid id: http://orcid.org/0000-0001-6902-3057

Wenner Glaucio Lopes Lucena - Universidade Federal do Pará - UFPA, Belém, PA (Brasil). E-mail: wdlucena@yahoo.com.br Orcid id: http://orcid.org/0000-0002-2476-7383

\section{WHERE IS THE COMPANY THAT WAS HERE? BANKRUPTCY AND RESTRUCTURING PROCESS OF KODAK IN THE LIGHT OF FIRM LIFE CYCLE THEORY}

Inajá Allane Santos Garcia, Dante Baiardo Cavalcante Viana Junior ${ }^{\Omega}$, Wenner Glaucio Lopes Lucena Universidade Federal do Pará - UFPA, Belém, PA (Brasil)

$\Omega$ Instituto Universitário de Lisboa - ISCTE-IUL, Lisboa (Portugal)

\section{ARTICLE DETAILS}

Article history:

Received: 8 February 2019

Accepted: 9 March 2020

Available online May: 01 th 2020

Double Blind Review System

Scientific Editor

Ilan Avrichir

\section{Key words}

Teaching Case

Firm's life cycle theory

Kodak

\begin{abstract}
Objective: In the light of the firm's life cycle theory, the present teaching case aims to present the trajectory covered by Kodak - a giant in the photographic market during practically the entire 20th century -, seeking to relate the business characteristics arising from the changes that occurred overtime with each stage of an firm's life cycle.

Method: The data for the construction of the historical context of the Kodak company was taken from several sources of traditional media, giving priority to the company's own website, digital newspapers of high international impact as well as national electronic magazines.

Relevance/originality: This teaching case offers a debate about the firm's life cycle theory, through the analysis of the trajectory of a real company, in an international context, allowing the identification of business characteristics that can raise the life cycle current organization.

Theoretical/methodological contributions: A triangulation is also sought between the firm's life cycle theory, the characteristics of the Kodak company and the various changes that have taken place in view of the various decisions taken towards restructuring the company.
\end{abstract}




\title{
¿DÓNDE ESTÁ LA COMPAÑÍA QUE ESTABA AQUÍ? BANCARROTA Y PROCESO DE REESTRUCTURACIÓN DE KODAK A LA LUZ DE LA TEORÍA DEL CICLO DE VIDA FIRME
}

\author{
Inajá Allane Santos Garcia, Dante Baiardo Cavalcante Viana Junior ${ }^{\Omega}$, Wenner Glaucio Lopes Lucena \\ Universidade Federal do Pará - UFPA, Belém, PA (Brasil) \\ $\Omega$ Instituto Universitário de Lisboa - ISCTE-IUL, Lisboa (Portugal)
}

\section{DETALLES DEL ARTÍCULO \\ Historia del Artículo: \\ Recibido: 08 de Febrero de 2019 \\ Aceptado: 09 de Marcha de 2020 \\ Disponible en línea: 01 de Mayo 2020 \\ Double Blind Review System \\ Editor Científico \\ Ilan Avrichir}

\section{Palabras-clave:}

Caso Docente

Teoría de los ciclos de vida de la empresa

Kodak

\begin{abstract}
RESUMEN
Objetivo: A la luz de la Teoría del Ciclo de Vida de la Firma, el presente caso de enseñanza tiene como objetivo presentar la trayectoria cubierta por Kodak, un gigante en el mercado fotográfico durante prácticamente todo el siglo XX, buscando informar las características comerciales que surgen de los cambios que ocurrió durante el paso del tiempo con cada etapa del ciclo de vida de una organización.

Método: Los datos para la construcción del contexto histórico de la compañía Kodak se tomaron de varias fuentes de medios tradicionales, dando prioridad al sitio web de la compañía, a los periódicos digitales de alto impacto internacional, así como a las revistas electrónicas nacionales.

Relevancia/originalidad: este caso de enseñanza ofrece un debate sobre la teoría de los ciclos de vida de la empresa, a través del análisis de la trayectoria de una empresa real, en un contexto internacional, que permite la identificación de las características del negocio que pueden elevar el ciclo de vida de la organización actual.

Contribuciones teóricas/metodológicas: también se busca una triangulación entre la Teoría de los ciclos de vida de la empresa, las características de la empresa Kodak y los diversos cambios que han tenido lugar en vista de las diversas decisiones tomadas para reestructurar la empresa.
\end{abstract}

Para citar este artigo:

Garcia, I., Viana Junior, D., \& Lucena, W. (2020). Cadê a Empresa que Estava Aqui? Processo de Falência e Reestruturação da Kodak à Luz da Teoria do Ciclo de Vida da Firma. Internext, 15(2), 107-119. doi: http://dx.doi.org/10.18568/internext.v15i2.523 